\title{
Satellite survey of gas flares: development and application of a Landsat-based technique in the Niger Delta
}

\author{
*O.C.D. Anejionu, G.A. Blackburn and J.D. Whyatt \\ Lancaster Environment Centre, Gordon Manley Building, \\ Lancaster University, Lancaster. United Kingdom, LA1 4YQ
}

\begin{abstract}
Pollution from oil and gas exploitation in the Niger Delta has greatly endangered the natural ecosystem, with gas flaring identified as a key agent of environmental pollution in the region. Efforts to evaluate the impacts of flaring on the surrounding environment have been hampered by limited access to official information on flare locations and volumes; hence an alternative method of acquiring such information is needed. This paper describes the development and application of the Landsat Flare Detection Method (LFDM), based on the combination of the near, shortwave and thermal infrared bands of Landsat imagery. The technique was validated using a reference dataset of flare locations interpreted from aerial photographs, achieving a user accuracy of $86.67 \%$. The LFDM was applied to a time-series of imagery (1984 to 2012 inclusive) to obtain a long term flaring history of the region; 303 flares (251 onshore and 52 offshore) were detected over the study period. The spatiotemporal distribution of these flares corresponds with known variations in oil and gas activities in the region. There was considerable variation between states in the trajectories of gas flaring activity and the proportion of onshore versus offshore flaring, which indicates substantial spatiotemporal variations in the environmental impacts of this industry. The LFDM builds upon existing methods of flare detection, which were based on moderate resolution imagery, by offering: increased precision of flare location estimates, improved objectivity, accurate identification of onshore and offshore flares and a long flaring history. The LFDM is an efficient and cost effective method which is able to provide local to regional scale information which is complementary to that derived from other remote methods of flare detection and ground-based surveys. It could thus be used for either backward (flare history) and/or forward (monitoring) surveys, especially in monitoring the country's progress towards the recently set $30 \%$ flare reduction target by 2017.
\end{abstract}

Keywords: Gas Flares, Oil Pollution; Thermal Infrared, Flare Detection, Landsat Time Series, Niger Delta 


\section{Introduction}

Nigeria is one of the largest crude oil producing countries in the world, with its daily production estimated at 2.6 million barrels/day as at 2004 (Vanguard Newspaper, 2012, 2011; NNPC, 2011). In addition to the crude oil found in the Niger Delta region of the country, there are considerable reserves of associated and non-associated natural gas, estimated to be in excess of 48.8 trillion cubic metres, making the country the 10th largest in the world in terms of proven natural gas reserves (NLNG, 2012). Decades of oil and gas exploitation have brought huge financial benefits to the country but also severe environmental problems that have endangered the region's fragile biodiversity. The Niger Delta ecosystem has thus been declared one of the most endangered ecosystems in the world (Nigerian Conservation Foundation, 2006). Environmental and health issues such as agricultural land and mangrove degradation, biodiversity loss, water and air quality degradation, and increasing risks to human health, have all been associated with oil and gas exploitation in the region (Chukwuezi, 2006; Ugochukwu, 2008).

Gas flaring (Figure 1) is a process used in separating natural gas associated with extracted crude oil (through burning). This is usually carried out at flow stations where crude oil from a group of wells in an oil field is initially gathered for processing. In Nigeria this practice has been ongoing since the commencement of oil exploration in 1958. Due to weak environmental regulations and enforcement in the country (World Bank, 2004), companies have found it more profitable to burn off the natural gas than to reinject or convert it to an energy source (Liquefied Natural Gas).

\section{Insert Figure 1 here}

Figure 1. Shell gas flare at Kolo Creek Bayelsa State, Nigeria, surrounded by agricultural fields (Source: Friends of the Earth, 2004a).

Among the oil producing countries, Nigeria currently has the second highest record of gas flaring (Elvidge et al., 2009a, 2009b, 2007; Friends of the Earth, 2004b; NLNG, 2012; Olukoya, 2008) and this has been identified as a key agent of environmental pollution in the region. There are strong indications that flaring has caused widespread environmental degradation via air pollution, heat stress, acid rain and soil bacteria reduction (NLNG, 2008; Zabbey, 2004). In addition, there have been continuous claims from host communities of directly experiencing the adverse effects of flares on their health and environment. Furthermore, in 2002 the World Bank reported that gas flaring in Nigeria had contributed more greenhouse gases to the atmosphere than any other source in sub-Saharan Africa (World Bank, 2002).

However, there is little auditable evidence of the magnitude of the impacts due to the inherent difficulty in obtaining reliable information about flaring from relevant agencies (GE Energy, 2011). Flaring usually occurs at remote and hazardous locations with restricted access, and public reporting of detailed flare related information (such as exact locations and flaring volumes) is usually discouraged by relevant government agencies through bureaucratic procedures. This restriction of access to information has thus greatly hindered comprehensive empirical assessment of the impact of flaring on the Niger Delta environment, and most research in this area has largely been speculative (Friends of the Earth, 2005). Remote sensing offers a potential solution to this through 
the detection, continuous monitoring and mapping of flare locations over extended periods. The following sections demonstrate the capabilities of remote sensing for detecting fires and gas flares, and explain the need for the new methodological approach developed in the present study.

\subsection{Detection of fires using satellite imagery}

In order to protect lives, properties and ecosystems, numerous satellite systems have been deployed to detect and monitor fires and their effects, due to their timely and repetitive observations, multispectral viewing capabilities, information retrieval from hazardous locations and synoptic detection capabilities. Fire detection is based on the ability of sensors to identify signals produced by fire from space. The two main types of signal employed for this purpose are the direct (flames and heat) and the indirect (smoke and burned surfaces). The direct signals are most commonly employed in fire detection (Movaghati et al., 2009; Justice et al., 2006; Weaver et al., 2003), while the indirect are employed for post fire assessment and management (Lanorte et al., 2013; Sedano et al., 2013). Most satellite-based fire detection studies have focused on forest/biomass fires, as their impacts draw considerable attention from the research community and investigations are facilitated by the availability of well-validated fire-hotspot algorithms (Dozier, 1981; Giglio et al., 2003; Kaufman et al., 2000; Martin et al., 1999; Matson and Dozier, 1981; Prins and Menzel, 1992). Fire detection from space is based on Planck's function (the temperature of a blackbody determines the characteristics of spectral radiation it emits). Radiation emitted at typical surface fire temperatures mostly lies in the infrared region of the electromagnetic spectrum. Thus, images from sensors such as Advanced Very High Resolution Radiometer (AVHRR), Moderate Resolution Imaging Spectroradiometer (MODIS) and Geostationary Operational Environmental Satellite (GOES), which have infrared bands, have mostly been used for forest fire detection (Ichoku et al., 2003; Justice et al., 2006; Kaufman et al., 1998; Li et al., 2000; Prins and Menzel, 1992). These systems also have relatively high temporal resolution, enabling near-continuous monitoring of active fire fronts, which is important given the ephemeral nature of biomass fires.

\subsection{Fire detection algorithms}

Four major classes of algorithms have been developed to detect fires using satellite images (Li et al., 2000; Martin et al., 1999). These techniques were developed initially using AVHRR data then adapted for data from different sensors.

The single band algorithm for fire hotspot identification was developed based on the AVHRR mid-infrared band $3(3.75 \mu \mathrm{m})$ (Malingreau and Tucker 1988). Typically, the radiative energy emissions of fires reach peak values at temperatures ranging between $500 \mathrm{~K}$ and $1000 \mathrm{~K}$ (Li et al., 2000). However, AVHRR band 3 pixels saturate at a brightness temperature of 320-331K (Robinson, 1991), as the sensor was not designed for fire detection. Despite this, band 3 can still be used to identify fire pixels as fire rarely saturate the pixels. So in its simplest form the fire detection algorithm retains all saturated or near-saturated pixels in AVHRR Band 3. In other forms, a single empirically-determined threshold is used to determine fire pixels in the Band 3. By using this approach, straw-burning was detected in Great Britain with AVHRR data (Muirhead and Cracknell, 1985) and biomass burning detected in the Amazon Basin of Brazil (Setzer and Pereira, 1991). The accuracy of single band threshold algorithms is 
greatly limited by the presence of bright objects such as highly reflective clouds and land surfaces. This can lead to false detections, restricting the utility of the single band algorithm for regional fire detection (Martin et al., 1999), and leading to the requirement for different thresholds for night-time data and day-time data, different ecosystems and different seasons. The single band algorithm was found to be most useful with night-time data, where the effects of solar irradiation are minimised (Martin et al., 1999).

The multi-band threshold algorithm was developed to improve upon the single band algorithm. It basically combines information (calculated brightness temperatures) from AVHRR band 3 and band 4 using two or more fixed thresholds for the bands, to determine fire hotspots. It generally involves: the use of band 3 to identify all potential fires, after which clouds are removed with band 4, and the difference in brightness temperature between bands 3 and 4 (T3-T4) is finally used to isolate fires from high temperature background. This is based on the notion that fire pixels have significantly larger values of T3-T4 than non-combusting background (Li et al., 2000). However, when a pixel is largely covered by an active fire, band 4 receives enough radiance to increase T4 up to saturation levels, in which case the test becomes inadequate. Another limitation is that thresholds are generally region-specific, thus modifications are required for different regions (Kennedy et al. 1994). The T3-T4 test, while efficient in removing false detections, is also limited as factors other than fire could create similar differences such as: (i) unequal atmospheric effects (ii) unequal emissivities; and (iii) solar reflection in band 3. The T3-T4 test works well for moderate resolution satellite images such AVHRR and MODIS (Kuenzer et al., 2008), where fires usually cover a small proportion of a $1 \mathrm{~km}$ pixel, but for higher resolution images such as Landsat, the test would not be as effective, as fires could easily occupy a large proportion of a 120/60m pixel (Li et al., 2000).

Contextual algorithm was developed to allow automatic adaptation of threshold values based on local conditions. Fixed threshold approaches are insensitive to spatiotemporal variations in land surface temperature and this can constrain the efficiency of the algorithms for fire detection (Martin et al., 1999). Contextual algorithms enable the continuous updating of threshold values based on the condition of surrounding pixels, thus accounting for variations in the local background signal. The basic process involves the initial setting of threshold values to identify potential fire pixels and then fine-tuning of the thresholds to confirm fires among the potential fire pixels (Li et al., 2000). The values of the neighbouring pixels to a target pixel serve as indicators of the radiometric characteristics of the local environment (Martin et al., 1999). The contextual algorithm was used in the development of the MODIS active fire detection product (Giglio et al., 2003).

Sub-pixel fire detection algorithms are used to detect fire and estimate fire size and temperature at sub-pixel level, through the decomposition of pixel responses into background and fire signals. This is based on the work of Dozier (1981) who found that this could be achieved using AVHRR bands 3 and 4 in areas of uniform background, if pixels were not saturated and the fire signal was significant in both bands. The algorithm is based on simultaneously solving two equations (Dozier model), derived from the two bands, to obtain sub-resolution brightness temperatures and the fractions of pixels occupied by fires, assuming the background temperature is known (Martin et al., 1999). However, it has been observed that the effectiveness of the sub-pixel approach is often limited due to violations of the underlying assumptions that: (i) pixels are unsaturated; (ii) any pixel is composed of only two uniform sets of temperature; 
high temperature (fire) and low temperature (background), (iii) all fires within a pixel are grouped together, (iv) both fire and background have black body emissivity properties, and (v) the background has spatially homogenous thermal properties (Peterson et al., 2013; Martin et al., 1999; Li et al., 2000). Furthermore, retrieved fire areas and temperatures can be extremely sensitive to the selection background temperature values (Langaas, 1993).

Consequently, recent operational fire detection algorithms from different sensors are based upon one or more of the first three classes of algorithms. Some prominent examples include: the Wildfire Automated Biomass Burning Algorithm (WF_ABBA), a contextual algorithm derived from the GOES imagery and ancillary databases (Prins and Menzel, 1992; Schmidt and Prins, 2005); the Bi-spectral Infra-red Detection (BIRD) hotspot detection, a contextual algorithm (Zhukov et al., 2006) based on BIRD image; the World Fire Atlas, a single threshold algorithm (Casadio and Arino, 2009) based on ATSR; the Meteosat SEVIRI fire detection algorithm, a hybrid contextual and multi-band approach (Roberts and Wooster, 2008); the Sentinel-3 Sea and Land Surface Temperature Radiometer (SLSTR) active fire detection, a hybrid contextual and multiband algorithm (Wooster et al., 2012); the MSG fire detection algorithms which include multi-band and contextual approaches (ATPS, 2013).

\subsection{Detection of gas flares using satellite imagery}

Although gas flares are numerous globally, only a small number of studies have attempted to detect them remotely. Croft (1978) was the first to suggest that flares were detectable through satellite images, having observed that they were visible in night-time Defence Meteorological Satellite Program (DMSP) and Landsat Multi-spectral Scanner System (MSS) images. Matson and Dozier (1981), while attempting to determine blackbody temperatures of sub-pixel fires from night-time AVHRR imagery, detected six gas flares in the Persian Gulf oil fields alongside twelve high temperature industrial sources (steel mills) in Detroit. Muirhead and Cracknell (1984) visually inspected AVHRR images in order to identify gas flares from North Sea oil rigs. Elvidge et al. (2007) used DMSP Operational Linescan System (OLS) imagery to identify flares visually, using the circularity and bright centres of lights from flares to aid detection, and was the first to attempt flare detection on a global scale over extended time period (1994-2008 inclusive). Although the DMSP method has high temporal resolution (12 hours revisit period), the relatively low spatial resolution $(560 \mathrm{~m}-2.7 \mathrm{~km})$ of the imagery greatly limits its ability to accurately detect flares, particularly amidst urban 'lightings' as noted by Elvidge et al. (2009a). Furthermore, gas flares are only detectable with nighttime DMSP, and flares in mid-to-high latitudes during the summer cannot be detected due to solar contamination limitations. In addition, the brightness of flares often leads to the saturation of the DMSP visible band, and lights from flow station facilities especially in remote flare locations are included in the gas flares signal captured by DMSP (Elvidge et al., 2011). Also, the visual identification technique employed is subjective and time consuming. Casadio et al., (2012) recently applied an active flame detection algorithm (ALGO3) to night-time Along Track Scanning Radiometer (ATSR) shortwave infrared imagery to globally detect flares from 19912009 inclusive. The method is a single-band fixed threshold algorithm that mostly employs temporal persistence of hotspot pixels as an indicator of flaring activity, with the presence of industrial installations (identified from high resolution images available on Google Earth) used to validate the results. However, the low spatial resolution 
$(1000 \mathrm{~m})$ of ATSR could reduce the spatial precision with which flares are located and hinder the detection of individual flares where two or more are in close proximity. Furthermore, the method of validation may be inconsistent as not all industrial sites in oil producing regions contain flares. Nevertheless, ALGO3 is more objective than the DMSP and AVHRR methods, as it adopts a fixed threshold method to discriminate hotspots based on the spectral characteristics of ATSR imagery in the automatic detection of flares, thus overcoming the limitations of manual identification.

Whilst the DMSP and ATSR methods of flare detection are clearly very useful for global studies of flaring, they may be of more limited utility in studies across smaller areas such as the Niger Delta, where detailed survey and monitoring of flares is needed for accurate assessment of the environmental and health impacts of flares from local to regional scales. Furthermore, the temporal coverage (1991 to 2009) of the outputs from the analysis of DMSP and ATSR data (Casadio et al., 2012; Elvidge et al., 2009a) limits the ability to comprehensively study the impact of flares in regions where gas flaring has been practiced over longer time periods. Hence, this study exploits the higher spatial resolution of Landsat imagery and its extended time-series for the detection of flares and assessment of the long term spatiotemporal variations in flaring.

\subsection{Detection of high temperature events using Landsat data and approach used in present study}

Landsat data have been employed in the detection and mapping of a wide spectrum of high temperature events such as underground coal fires (Cracknell and Mansor, 1992; Prakash et al., 1997; Kuenzer et al., 2007), geothermal sources (Kienholz et al. 2009; Savage, 2009), fumarolic fields (Lagios et al., 2007), and volcanic activity (Flynn et al, 2001; Goanac'h et al., 1994; Francis and Rothery, 1987). Indeed in relation to the oil industry, Kant and Badarinath (2002) successfully deployed Landsat data to detect oil spill fires. However, despite the level of success of Landsat data in the detection of high temperature events and suggestions that gas flares could be detected with Landsat infrared bands (Croft, 1978; Elvidge et al., 2009a, 2009b, 2007), no study has demonstrated the detection of gas flares with Landsat data.

In the context of the present study Landsat data was chosen as an appropriate sensor due to its relatively high spatial resolution. Existing techniques for fire detection have been designed for larger fires that are ephemeral in nature and usually focus on near-realtime monitoring of the development and progress of fires. Thus, low spatial resolution sensors such as AVHRR with higher temporal resolutions have effectively been employed for the development of the algorithms. The comparatively large size of biomass fires minimises the effect of using low spatial resolution imagery on the accuracy of detection. In contrast, gas flares are much smaller in size, have a permanent location and are mostly continuously active (Environmental Rights Action/Friends of the Earth, 2005; SPDC, 2011). Thus using low spatial resolution imagery to detect such small features is likely to prove less effective than using higher spatial resolution imagery such as Landsat and it has been observed that existing fire detection algorithms usually fail to detect gas flares (Elvidge et al., 2010). A Landsat-based flare detection technique is also expected to improve the spatial precision of flare detection compared to previous studies that employed moderate spatial resolution imagery (DMSP and ATSR), while retaining simplicity and objectivity. High precision detection will play an invaluable role in monitoring the compliance of individual companies to the current commitments to flaring reduction within Nigeria.Hence, the potential advantages of 
Landsat data for detecting gas flares can be summarised as: (i) Landsat has good spatial resolution suitable for accurate detection of flares which are high temperature events but have a small spatial extent; (ii) the fixed location and near-continuous nature of flares implies that the relatively low temporal resolution of Landsat imagery is unlikely to be detrimental to the detection process; (iii) the long archive of Landsat data and continuation of the time-series with the recently launched Landsat 8, make this system amenable to longer term detection of spatiotemporal changes in flaring; (iv) Landsat data is freely available, readily accessible, and easy to process, and it therefore presents a potentially cost-effective solution.

The need to develop a new algorithm for detecting gas flares from Landsat data is based on the following: (i) most existing fire detection algorithms utilise information from mid- and thermal-infrared bands but Landsat does not possess the former; (ii) at the spatial resolution of Landsat the heterogeneity of land cover characteristics (and their spectral responses) in the vicinity of gas flares limits the effectiveness of contextual algorithms; (iii) sub-pixel fire detection algorithms are generally unsuitable due to the unrealistic assumptions of the model and are inappropriate given the spatial resolution of Landsat data; (iv) existing Landsat-based methods for detecting other high temperature events are generally unsuitable as they have been calibrated for quite different phenomena or require manual intervention to set thresholds. Therefore, the present study extends the existing analysis methods through the use of multi-band fixedthreshold algorithms to harness the flare detection capabilities of the near, shortwave and thermal infrared bands of Landsat.

The Landsat Flare Detection Method (LFDM) has been designed to provide an accurate and objective means of detecting onshore and offshore flares, using a transferrable and repeatable method that is simple, cheap, quick and efficient, and facilitates the derivation of 'flare histories' over extended time periods. This study sets out to achieve the following objectives:

i. to explore the flare detection potential of the different Landsat spectral bands,

ii. to develop a remote sensing technique based on Landsat imagery for the automatic detection of flares in the Niger Delta region,

iii. to apply the technique in the survey and mapping of active flares in the region, covering the three decades in which oil extraction has been most active.

\section{Study Area}

The Niger Delta region in southern Nigeria covers an area of approximately $70,000 \mathrm{~km}^{2}$. It is a densely populated region with over 10 million people and it is endowed with extensive natural resources (Zabbey, 2004). Apart from being the largest source of hydrocarbons in the country (Tuttle et al., 1999) and the centre of oil and gas industry in Nigeria (Figure 2), it is home to the third largest mangrove forest in the world and has a rich biological diversity (Niger Delta Awareness, 2007). The Niger Delta is characterised by wetlands, estuaries and rivers traversing the entire region and can be divided into three main ecological zones, with varying boundaries depending on seasonal flooding patterns: the saltwater mangrove swamps, the fresh water swamp and lowland rainforests (Nzewunwa, 1979). The region provides the natural habitat for a wide variety of endemic coastal and estuarine fauna and flora, supporting over $60 \%$ of the total species in Nigeria (IUCN, 1994; World Bank, 1995, cited in Ugochukwu 2008). Hence, the Niger Delta is ranked as one of the highest conservation priorities in 
West Africa, yet is virtually unprotected (IUCN, 1994). It has thus been the focus of increasing research activity in recent years, particularly on the impacts of oil exploitation on the environmental (Eregha, and Irugh, 2009; Bayode et al., 2011; Nwaogu and Onyeze, 2010), socio-cultural and economic (Aghalino, and Odeh, 2010; Ajiboye et al., 2009) characteristics of the region.

Insert Figure 2 here

Figure 2. The Niger Delta region, its component states and oil producing area. Map of Nigeria is inset.

\section{Methodology}

\subsection{Data and preprocessing}

The main data used in this research include Landsat imagery obtained from the Global Visualization Viewer (USGS, 2012), high resolution aerial photographs from Google Earth, and a political map of Nigeria delineating state boundaries, obtained from the Department of Geoinformatics and Surveying, University of Nigeria Nsukka. The core oil producing area is covered by approximately four Landsat scenes and data from the Thematic Mapper (TM4, TM5), and Enhanced Thematic Mapper Plus (ETM+) sensors extending from 1984 to 2012 were used. Landsat MSS data were not used in this study because there is no thermal band in this sensor. The Landsat data were only available in day-time and there was no night-time Landsat data for the region. Due to limitations imposed by the availability of cloud-free Landsat products, and differences in satellite path between some scenes, it was not possible to obtain all four scenes that covered the study area on exactly the same occasion. Instead our strategy was to break down the study period into six sampling periods and use one image of each scene acquired during the six different sampling periods between 1984 and 2012 (Table 1). It was anticipated that these snapshots of active flares for each scene would provide insightful details of flaring activities in the region, by detecting changes in the spatial distribution of the flares over the study period. Each image selected was of the highest quality (minimal cloud coverage and atmospheric attenuation) during that sampling period and, as far as possible, matched the acquisition dates of the images covering the other scenes during that period. Due to gaps in the USGS Landsat data archive, only a limited number of images were available between 1991 and 1998 for the region, and none were suitable for this study due to extensive cloud coverage. Imagery acquired after May 2003 suffered from missing slithers of data towards the edge of the swath due to the scan line corrector failure of the ETM+ sensor. Therefore, it was necessary to fill the gaps using data from temporally adjacent ETM+ scenes, to ensure full coverage of the study area.

Table 1. Landsat images of a section of Niger Delta, Nigeria used in the study. Insert Table 1 here

Before delivery, the Landsat data used had been radiometrically, geometrically and terrain corrected to Level 1 using the standard algorithms (NASA, 2011). Our analysis of the various data sets revealed that these algorithms had worked very effectively and that no further refinements to these corrections were required. We then converted the 
raw digital number (DN) values in the Landsat bands to spectral radiance values $\left(\mathrm{W} \mathrm{m}^{-2}\right.$ $\mathrm{sr}^{-1} \mu \mathrm{m}^{-1}$ ) using the following standard algorithm, using the LMin and LMax spectral radiance scaling factors available in the metadata file for each Landsat scene (NASA, 2011):

$$
L_{\lambda}=\frac{L_{\max \lambda}-L_{\min \lambda}}{\boldsymbol{Q}_{\text {cal } \max }-\boldsymbol{Q}_{\text {cal } \min }} * \boldsymbol{Q}_{\mathrm{cal}}-\boldsymbol{Q}_{\text {cal } \min }+L_{\min \lambda} \ldots \ldots \ldots \ldots
$$

Where:

$$
\begin{aligned}
& L_{\lambda}=\text { spectral radiance at the sensor's aperture }\left(\mathrm{W} \mathrm{m} \mathrm{m}^{-2} \mathrm{sr}^{-1} \mu \mathrm{m}^{-1}\right) \\
& \boldsymbol{Q}_{\text {cal }}=\text { the quantized calibrated pixel value }(\mathrm{DN}) \\
& L_{\lambda}=\text { spectral radiance scaled to } \boldsymbol{Q}_{\text {cal min }}\left(\mathrm{W} \mathrm{m} \mathrm{mr}^{-1} \mu \mathrm{m}^{-1}\right) \\
& L_{\max \lambda}=\text { spectral radiance scaled to } \boldsymbol{Q}_{\text {calmax }}\left(\mathrm{W} \mathrm{m}^{-2} \mathrm{sr}^{-1} \mu \mathrm{m}^{-1}\right) \\
& \boldsymbol{Q}_{\text {cal min }}=\text { minimum quantized calibrated pixel value }(\mathrm{DN}, \text { usually }=1) \\
& \boldsymbol{Q}_{\text {calmax }}=\text { maximum quantized calibrated pixel value }(\mathrm{DN}, 255)
\end{aligned}
$$

The Landsat thermal bands were subsequently converted to temperature values (Kelvin) using the inverse of the Planck function shown below (NASA, 2011):

$$
T=\frac{K_{2}}{\ln \left[\frac{K_{1}^{*} \varepsilon}{L_{\lambda}}+1\right]}
$$

Where:

$T=$ effective at-satellite temperature (Kelvin)

$K 2=$ calibration constant $2(1282.71$ for Landsat 7 and 1260.56 , Landsat 5)

$K 1=$ calibration constant 1 (666.09Landsat 7 and 607.76 Landsat 5)

$\varepsilon=$ emissivity (typically 0.95 )

$L_{\lambda}=$ spectral radiance $\left(\mathrm{W} \mathrm{m}^{-2} \mathrm{sr}^{-1} \mu \mathrm{m}^{-1}\right)$

The various Landsat datasets were then inter-calibrated to minimise differences due to atmospheric attenuation and environmental temperature across years and scenes. To do this the 2002 Landsat image of scene 2 was chosen as the reference based on image quality (cloud free and minimal distortion) and temporal centrality (approximately midway between the start and end years of study period) and all other images were calibrated to this reference. Spatially homogenous and spectrally stable calibration sites were extracted from areas of scene overlap and radiance or temperature values from each band in target and reference images were regressed in order to construct a calibration model for each band. The model was then used to inter-calibrate each band in the target image with the reference image. This was effectively an adapted empirical line correction (Karpouzli and Malthus, 2003) that used a reference image rather than reference ground spectra, as these were not available for the study site, due to access difficulties.

\subsection{Development of the Landsat Flare Detection Method (LFDM)}


The sensitivities of each Landsat band were independently investigated through interactive examination to determine their flare detection capabilities. The infrared bands (4, 5, 6 and 7) were found to exhibit the greatest potential for discriminating flares, with bands 5 and 7 (both in the shortwave infrared region) apparently showing almost similar potential. Further examination revealed that Band 7 was more sensitive to flares than band 5 as more pixels were highlighted as flares by band 7 . The low-gain thermal band $\left(6_{1}\right)$ was found to have greater capability than the high-gain band $\left(6_{2}\right)$ in discriminating flares from biomass fires and hot natural and anthropogenic surfaces. Band 4 which exhibited flare detection potential was chosen as it was from the near infrared range and have the potential to detect other flare characteristics that may have been missed by the shortwave infrared bands. Therefore, the three Landsat infrared bands that were selected (bands 7, 61 and 4) provided the greatest discriminatory power for flare detection. The three bands were subsequently used in combination to develop the multiband flare detection technique. We observed from the bands that the influence of gas flares extended to more than 1 pixel (Figure 3), thus sub-pixel problem due to the differences in the spatial extent of flares did not pose a significant problem.

\section{Insert Figure 3 here}

Figure 3. Illustration of the depiction of gas flares with differing spatial extents on Landsat imagery of a section of Niger Delta

A range of different thresholds were tested on the individual infrared bands and accuracy assessments performed, in order to determine optimal thresholds and technique for flare detection.

The multi-band fixed-threshold method established is made up of three key criteria. The first criterion focuses on identifying locations with high shortwave infrared emissions. According to Wien's displacement law, as the temperature of a body increases, peak emission shifts towards the shorter wavelengths and at temperatures of about $1150 \mathrm{~K}$, which approximates average flaring temperature (Biogas, 2006), the peak emission is within the shortwave infrared (Dennison and Roberts, 2009). Hence, due to the sensitivity of the shortwave infrared to fire radiative temperature, Landsat band 7 was used as the first criterion for flare detection. Pixels in band 7 with radiance values greater than the optimal threshold value $\left(10.5 \mathrm{Wm}^{-2} \mathrm{sr}^{-1} \mu \mathrm{m}^{-1}\right)$ were selected as high shortwave infrared emission events. However, it was found that other features on the image with high shortwave infrared emissions or high levels of reflected solar radiation such as biomass fires, clouds, bare land and sandy surfaces could exceed this threshold.

Therefore, to discriminate flares from other objects with high shortwave infrared responses, a second criterion was introduced, which identifies high temperature pixels in the thermal band (band 6 for TM and band $61-$ low gain band - for ETM+). An optimal threshold value of $(310 \mathrm{~K})$ was found to achieve a balance between over- and under-representation of flare pixels. It was found that there were spatial offsets between band 6 and the other infrared bands, which could not be explained by the differences in spatial resolution of the bands and were inconsistent in terms of magnitude and direction between different Landsat datasets. To account for such variability in offsets, spatial buffering was applied to the pixels generated by thresholding band 7 , before these were combined with the outputs from band 6 . The buffering also minimised the effects of varying directions of the flames (due to the action of wind) between locations and over time. Different buffering radii were examined before arriving at an optimum 
radius of $300 \mathrm{~m}$. By combining the outputs from bands 7 and 6 , the resulting pixels represented features with high shortwave and thermal infrared responses and this eliminated most of the areas falsely identified as flares based on band 7 alone.

As the near infrared band was found to exhibit some potential for flare detection, a further refinement (particularly for onshore flares) to the method used a third criterion that identified high near-infrared events from band 4. An optimal threshold value of 21 $\mathrm{Wm}^{-2} \mathrm{sr}^{-1} \mu \mathrm{m}^{-1}$ was used and the resulting pixels were overlaid with the outputs from the band 7 and 6 combination so that pixels exceeding the thresholds in all three bands formed the final output from the flare detection technique. The main stages of the Landsat Flare Detection Method (LFDM) are illustrated in Figure 4.

\section{Insert Figure 4 here}

Figure 4. Major stages of the Landsat flare detection method (LFDM). Band 4 (radiance $\mathrm{Wm}^{-2} \mathrm{sr}^{-1} \mu \mathrm{m}^{-}$ ${ }^{1}$ ), band $6_{1}$ (temperature $\mathrm{K}$ ), band 7 (radiance $\mathrm{Wm}^{-2} \mathrm{sr}^{-1} \mu \mathrm{m}^{-1}$ )

In order to provide some context for the capabilities of the LFDM, the flare detection potential of a wide range of alternative analytical image processing techniques was tested. For brevity, only the more successful approaches are described here. Supervised classification was attempted and the optimal configuration for the discrimination of flares was to utilise all of the Landsat bands with a minimum distance classifier to map five land cover classes (water body, vegetation, bare land, built environment and gas flares,). Similarly, Principal Component Analysis (PCA) was applied to all Landsat bands to generate three Principal Component images. These were subsequently classified into the five land cover classes listed above, using the minimum distance classifier. Accuracy assessments (see section 3.5) enabled quantitative comparison of the different approaches to flare detection.

\subsection{Mapping flares with the LFDM}

The technique was subsequently applied to the full time series of Landsat images covering the entire Niger Delta region (as listed in Table 1). A flaring history model detailing the spatial and temporal variations in the distribution of active flares in the region was subsequently developed from the results. The Nigerian political map was used to allocate the detected flares to different states in the region. As the map did not delineate the offshore boundaries of the states, offshore flares were objectively assigned to the nearest states using GIS tools in order to adequately represent the flaring activity of the states. The ecological zones in which the flares are located were also examined in order to understand potential environmental impacts.

\subsection{Accuracy Assessment}

Ground-based surveys of flare locations were not feasible at the time of research due to logistical and safety issues associated with fieldwork in the region resulting from political volatility. Therefore, high resolution aerial photographs from Google Earth were analysed visually in order to validate the Landsat-based flare detection procedures. This method for collecting reference data on flare locations has been employed effectively by previous researchers (Casadio et al., 2012; Elvidge et al., 2009b). Landsat images closely corresponding $( \pm 1$ month) with the acquisition date of the high resolution images were used to detect flares using the LFDM, supervised classification 
and PCA methods. For each of the detected flare locations, the high resolution aerial photography was investigated manually. Visible flames were used in conjunction with clearly discernible physical structures such as buildings, pipelines, flare pits and flare stacks to confirm the locations of active flares. The precise coordinates of visibly active flares were noted. If flares were absent from the location indicated by the Landsat procedures then the land cover type present was visually interpreted from the photography and noted. The total number of correct and incorrect identifications were used to compute the user accuracy - the percentage of the total flares derived from the Landsat data that were correctly identified. This measure of accuracy was considered appropriate as the focus was on maximising the proportion of correct identifications and higher user accuracy implies higher confidence in the use of the flare detection technique. The spatial accuracy of the Landsat-based methods was calculated by comparing the coordinates of the flares detected from Landsat with the coordinates of the corresponding flares in the reference dataset.

\section{Results}

\subsection{Accuracy of the flare detection techniques}

A user accuracy of $86.66 \%$ was obtained from the LFDM, 54.71\% from supervised classification, $36.14 \%$ from band 6 threshold, and $34.38 \%$ the classified principal component. This level of accuracy from the LFDM is in line with that of many remotesensing based detection and mapping methodologies and justifies the onwards application of the LFDM approach in this study. The spatial accuracy of the LFDM calculated as the root mean square error between locations of the flares in the reference data and those identified by LFDM was found to be $\pm 23.85 \mathrm{~m}$ (Figure 5). Details of the data used within the validation procedures are shown in Table 2.

Insert Figure 5 here

Figure 5. Illustration of the spatial accuracy of LFDM in flare detection using an active gas flare in a section of the Niger Delta. Red marker indicates the location derived from the LFDM.

Insert Table 2 here

Table 2. Details of the flares identified by LFDM during validation

\subsection{Flare Distribution}

The LFDM detected 303 flares (251 onshore and 52 offshore) in the region during the period of study (1984 to 2012 inclusive). Figure 6 shows the spatial distribution of the flares and the number of sampling periods during which they were detected, represented by graduated symbols. Figure 6 also show that a considerable number of flares were detected on multiple occasions, suggesting that the environmental impacts of flaring in this region have been experienced for a sustained period of time. While analysing the temporal variations of the flares across the states, Rivers State was found to have the greatest number of sustained active flares, closely followed by Delta State (see Table 3), suggesting that environmental impacts would be greatest in these states. Table 3 also shows the number of flares detected during each sampling period and their onshore/offshore distribution, which indicates that the largest number of flares (143) 
was recorded in the 2006-2009 time period. Akwa Ibom State had the greatest number of offshore flares (17), closely followed by Delta State (15). Further analysis revealed the onshore and offshore contributions of the various states during the various sampling periods (Table 4).

\section{Insert Table 3 here}

Table 3. Distribution of flares across states and numbers detected in each time period.

\section{Insert Table 4 here}

Table 4: Number of offshore and onshore flares detected in various sampling periods across the states

\section{Insert Figure 6 here}

Figure 6. Spatial distribution and persistence of detected flares in the Niger Delta from 1984 to 2012

In order to get better understanding of the spatial and temporal variations in offshore flares, their distribution was analysed separately (Table 3, lower part). Most of the offshore flares detected in the early years (1984-1987) were located around Delta State offshore areas, and whilst newer offshore flares (from 1999) were detected around the Rivers and Akwa Ibom States offshore areas. This is in line with current trend in offshore exploration activities, which have been intensified in the eastern part of the Niger Delta, with the discovery of new offshore oil fields (Bonga Field, Oyo Field, Ofon Field, Usan Field and Egina Field). Approximately 45\% of flares detected in Akwa Ibom State were located offshore, while Rivers State, with the greatest number of flares (overall) has only around 10\% located offshore. This suggests that relative impacts on marine and terrestrial environments are likely to vary substantially between states. Figure 7 shows that within the terrestrial environment, sustained gas flaring activity has taken place within all of the three main ecological zones of the region.

\section{Insert Figure 7 here}

Figure 7: Map showing the distribution of gas flares among the major ecological zones of the Niger Delta.

\section{Discussion}

This study has demonstrated the viability of using Landsat imagery to accurately detect flares from space. It potentially provides a simple, objective and cost effective means of monitoring flaring activity. The spatial accuracy obtained, surpasses those of previous methods based on coarser spatial resolution imagery (Muirhead and Cracknel, 1984; Elvidge et al., 2009a; Casadio et al., 2012), and hence will be beneficial for investigating the impacts of flares from local to regional scales. As flares are clearly discernible from high resolution imagery (as shown in our validation exercise), it could be argued that employing such imagery may offer even higher spatial precision than the Landsat method. However, the cost of repeatedly acquiring high resolution imagery for monitoring flares would be prohibitive given the size of the area under investigation; meanwhile, Landsat imagery is freely available. Due to the long archive of Landsat 
imagery, the study was able to provide a longer flaring history than previous satellite based flare studies, allowing for the first time an assessment of the flaring activity in the Niger Delta from the mid 1980's to present. This is valuable for understanding the impacts of flares over the extended period of oil extraction activities in the Niger Delta. With the recent launch of Landsat 8, the LFDM has potential for monitoring gas flaring activity in the future.

The spectral detection capabilities of Landsat proved to be suitable for the accurate discrimination of flares from other land surface covers. The LFDM exploited the combination of responses across the three infrared bands and the simple technique offered an objective method without the need for painstaking manual interpretation. The use of radiance and temperature values for defining thresholds will facilitate the transferability of the method to Landsat imagery of other parts of the world.

It is worth noting that results obtained from the LFDM may have been affected by the temporal resolution of Landsat that limited the number of images that were acquired for the study area. The number of useable images was further restricted by cloud cover which is high and persistent in this region. As cloud-free images were used in the analysis then, in principle, all areas of the study site received equal sampling effort. However, image acquisition dates did vary across the study site within each sampling period because it was necessary to (i) use images from a variety of years within each sampling period in order to obtain all the scenes needed to cover the entire study site and (ii) fill data gaps caused by the scan line corrector failure after 2003 using temporally adjacent ETM+ imagery (but the number of useable images did increased substantially for the later sampling periods). Hence, it could be argued that uneven temporal coverage of data and the generally restricted frequency of useable Landsat data could have resulted in the under-sampling of flares. However, it is important to recognise that gas flaring is carried out as long as crude oil is being processed because the gas extracted from the processed oil must be constantly expelled due to health and safety reasons (Argo, 2013). Gas flares are usually considered permanent phenomena that are burning continuously at any active flow station, except for short periods of maintenance, when oil processing may be briefly halted. Therefore, we do not expect the reduced frequency of Landsat data to drastically reduce confidence in the spatial and temporal distributions of the flares reported in this research. Furthermore, given the large financial investment needed to construct flow stations and associated flaring infrastructure, oil companies expect such facilities to operate for decadal time scales in order to see adequate returns (Daily Champion Newspaper, 2003). Hence, it could be argued that permanent changes such as flare commissioning or decommissioning and associated long term trends in flaring activity will be adequately characterised with the six sampling periods used in the study.

Solar irradiation effects in day-time images, were another challenge that may have affected our method, leading to the incorrect identification non-flare pixels as flares. Day-time data were used in this project as there was no available night-time Landsat data for the region. As part of our methodological development process, investigations of the responses of individual Landsat bands revealed that some potential flare detections were caused by sun glint from high reflectance surfaces such as exposed soil, rooftops, road surfaces and river sands. However, despite the challenges of the day-time data, we were able to develop the sequential multi-band thresholding approach which was able to minimise false detections due to high reflectance surfaces and produce a good level of detection accuracy. Nevertheless, false detections were not completely removed using the LFDM and it might be expected that for regions where night-time 
Landsat data are available, the technique would perform with improved accuracy. Furthermore, the availability of night-time Landsat data may increase the temporal sampling frequency.

The LFDM has potential to make important contributions in environmental and socioeconomic research into the effects of gas flaring in the Niger Delta, being the first attempt to identify flare locations using an approach that avoids reliance on restricted official documentation. Given that the Niger Delta is among the highest ranked global hotspots for gas flaring, this is a significant contribution to our understanding of the magnitude and dynamics of this environmental challenge. Furthermore, the technique developed here could be extended to other flaring hotspots in order to monitor oil producing countries' compliance to the Kyoto Protocol aimed at the reduction of greenhouse gas emissions. It is also anticipated that the LFDM in conjunction with high temporal resolution imagery, will play major role in monitoring Nigeria's compliance to the $30 \%$ gas flaring reduction target by 2017 recently set by the World Bank Global Gas Flaring Reduction partnership (World Bank 2012). The research has extended the earlier work on flare detection through satellite imagery (Elvidge et al., 2009; Casadio et al., 2012), from a general global observation to a more focussed regional survey and monitoring process.

Significantly, this research was able to report on the trajectories of gas flaring activity at the state scale, which provides more explicit evidence of the changes in the oil exploitation process to policy makers and environmental managers in the country. Moreover, the variation of the flares within each of the states of the Niger Delta over time enabled us to gain a much finer (spatially and temporally disaggregated) understanding of the process compared to the official regional values as reported by the NNPC (NNPC, 2011). This knowledge provides a solid basis for future assessment of the environmental impacts of gas flaring in the region. The length of time a flare has been active is expected to be proportional to its impact on the environment, as every cubic metre of gas flared contains a considerable percentage of carbon dioxide, carbon monoxide, soot, methane, as well as recognised toxins, such as benzene benzapyrene, dioxin, benzene, toluene, nitrogen dioxide, and particulates, which are directly released into the atmosphere (Odu, 1994; Climate Justice Programme, 2005). Hence, not only does the regional total of gas flares detected in this study indicate remarkable levels of pollutant release, the state-specific distributions suggest that there are intense hotspots of prolonged activity and impact. Notably, Rivers State has by far the greatest number of flares and likely the greatest volume of pollutants released since 1984, with $33 \%$ of all flares in the region located in this state. The research has also demonstrated that there has been a prolonged activity of gas flaring across all of the ecological zones of the region, suggesting that localised impacts of flaring are likely to have an influence upon all of the major components of biodiversity within the Niger Delta. The knowledge of flaring activity generated in this project can now form a basis for quantifying the local and regional scale environmental impacts and consequences for biodiversity and ecosystem services, which will be undertaken in our future research. The first step in this process will be to estimate the rate of gas combustion of individual flares. This may be possible through the fusion of outputs from the localised LFDM with information from a range of other operational satellite systems that offer the possibility of measuring signals from flares and their atmospheric pollutants over different spatial, temporal and spectral domains. 


\section{Conclusions}

Gas flaring is a key agent of environmental pollution in the Niger Delta region of Nigeria. Efforts to comprehensively assess the impact of flaring on the Niger Delta ecosystem have been hampered by limited information on flaring locations and volumes. In this paper, we describe the development of a technique to detect gas flares using Landsat imagery. The LFDM is a multiband fixed threshold technique based on the combination of the flare detection capabilities of the shortwave, thermal and near infrared bands of Landsat. The LFDM was validated with a reference dataset of gas flare locations obtained from high resolution aerial photographs, achieving a user accuracy of $86.67 \%$. When applied to the Niger Delta region, the LFDM was able to provide long term profiling of variations in flaring activity; it detected 303 active flares, comprised of 251 onshore and 52 offshore flares, within the period of study. A considerable number of flares have been active throughout the 28 years study period, suggesting sustained impact on the environment. The results obtained from the LFDM were subsequently used to spatially and temporarily disaggregate the regional flaring activity reported by the NNPC into a more meaningful and explicit state level. Rivers State contained the highest number of flares overall, closely followed by Delta State, while Akwa Ibom State had the highest number of offshore flares. Rivers State contained a third of the gas flares in the region and with its high percentage of onshore flares $(90 \%)$, the impact is likely to be concentrated in the terrestrial environment inhabited by humans. Sustained flaring activity has taken place within all of the major ecological zones of the delta, suggesting that a wide range of biodiversity components and ecosystem services are likely to be affected by this activity. These findings in relation to the spatio-temporal distribution of gas flaring activities will be invaluable for future environmental and socioeconomic research related to the oil industry in the Niger Delta region.

The LFDM overcame many of the limitations of techniques that have used moderate resolution satellite imagery for flare detection (such as difficulty in detecting flares amidst urban lighting and the need for visual identification of flares) and those of conventional surveying methods (such as being time consuming and costly), by making use of the spectral characteristics and relatively high spatial resolution of Landsat imagery. The technique is simple, objective, cost effective and accurate. It enables the mapping of flares with a higher spatial precision than previous remote sensing techniques and monitoring over extended periods of time. The LFDM therefore has the capacity to contribute to global flare monitoring exercises, by providing detailed information on gas flaring activities from local to regional scales that is complementary to that from other sources. Further analyses of the robustness and transferability of the technique are now needed to develop the wider applicability of the approach. A specific focus of our future research will be on using Landsat imagery in combination with data from other missions, to improve estimates of the rate of gas combustion by individual flares. This will form the basis for the subsequent modelling of the health and environmental impacts of flaring in the Niger Delta and other oil-producing regions.

\section{Acknowledgements}

We wish to acknowledge the Surveyors Council of Nigeria (SURCON), who partly supported the initial stages of this project with a research grant, the Department of Geoinformatics and Surveying, University of Nigeria Enugu Campus, for the provision 
of the political map used in this research and the Petroleum Technology Development Fund (PTDF Nigeria) who sustained the later stages of this research via a Scholarship. Thanks also to Simon Chew (Lancaster Environment Centre), for his expert advice on the refinement of the figures used.

\section{References}

ATPS (AFRICAN TECHNOLOGY POLICY STUDIES NETWORK), 2013, Multi-temporal threshold algorithm in forest fire detection using MSG satellite: The case of Zimbabwe. ATPS working paper no. 76.

ARGO FLARE SERVICES, 2013, Flare system design. Flare brochure. http://www.argoflares.com/about-argo-flare-services/literature/ (accessed on 10th May, 2013).

AGHALINO, S.O., ODEH, L. E., 2010, Social and cultural impact analysis of oil exploitation production in the Niger Delta region of Nigeria, in: Ojakorotu, V., Isike, C. A. (Eds.), Oil politics in Nigeria. Lambert Academic Publishing, Saarbrücken Germany, pp. 126-139.

AJIBOYE O.E., JAWANDO J.O., ADISA W.B., 2009, Poverty, oil exploration and Niger Delta crisis: The response of the youth. African Journal of Political Science and International Relations, 3 (5), pp. 224-232.

BAYODE, O.J.A., ADEWUNMI, E.A., ODUNWOLE, S., 2011, Environmental implications of oil exploration and exploitation in the coastal region of Ondo State, Nigeria: A regional planning appraisal. Journal of Geography and Regional Planning, 4(3), pp.110-121.

BIOGAS TECHNOLOGY LTD., 2006, Procedure to determine the flare efficiency based on the flame temperature in an flare. http://cdm.unfccc.int/filestorage/C/6/X/C6XWJCBZSTR2S0SQKE7ZFQYEDIBNPZ/Pro cedure $\% 20$ to $\% 20$ determine $\% 20$ the $\% 20$ flare $\% 20$ efficiency $\% 20$ based $\% 20$ on $\% 20$ the $\% 20 \mathrm{f}$ lame\%20temperature\%20in\%20an\%20enclosed\%20flare.pdf?t=U0F8bWJ6dHFjfDCd5s hjDqJtuWZXiKa1LFz5 (accessed on $2^{\text {nd }}$ May, 2012).

CASADIO, S., ARINO, O., 2009, A new algorithm for the ATSR World Fire Atlas. Proceedings EARSEL $2009 \quad$ Symposium. http://due.esrin.esa.int/wfa/Casadio_Arino_Earsel_2009.pdf. (accessed on 23rd July, 2012).

CASADIO, S., ARINO, O., SERPE, D., 2012, Gas flaring monitoring from space using the ATSR instrument series. Remote Sensing of Environment, 116, pp.239-249.

CHUKWUEZI, C., 2006, Oil exploration and human security in Nigeria: a challenge to sustainable development. http://www.jsdafrica.com/Jsda/Fall2006/PDF/Arc_Oil\%20Exploration.pdf (accessed on $2^{\text {nd }}$ February, 2011).

CLIMATE JUSTICE PROGRAMME., 2005, Gas flaring in Nigeria: A human rights, environmental and economic monstrosity. http://www.foe.co.uk/resource/reports/gas flaring nigeria.pdf (accessed on $2^{\text {nd }}$ February, 2011)

CRACKNELL, A.P., MANSOR, S.B., 1992, Detection of sub-surface coal fires using Landsat Thematic Mapper data. International Archives of the Photogrammetry, Remote Sensing and Spatial Information Sciences, 29(b7), pp.750-753.

CROFT, T.A., 1978, Nighttime images of the earth from space. Scientific American, 239, pp. 68-79.

DAILY CHAMPION NEWSPAPER, 2003, Nigeria: Shell builds locally fabricated flow station. (29th September, 2003).

DENNISON, P.E., ROBERTS, D.A., 2009, Daytime fire detection using airborne hyperspectral data. Remote Sensing of Environment, 113, pp. 1646-1657. 
DOZIER, J., 1981, A method for satellite identification of surface temperature fields of subpixel resolution, Remote Sensing of Environment, 11, pp. 221-229.

ELVIDGE, C.D., BAUGH, K.E., TUTTLE, B.T., HOWARD, A.T., PACK, D.W., MILESI, C., ERWIN, E.H., 2007, A twelve year record of national and global gas flaring volumes estimated using satellite data. Final report to the World Bank. http://siteresources.worldbank.org/INTGGFR/Resources/DMSP_flares_ 20070530_bsm.pdf (accessed on 11th October, 2009).

ELVIDGE, C.D., ZISKIN, D., BAUGH, K.E., TUTTLE, B.T., GHOSH, T., PACK, D.W., ERWIN, E.H., ZHIZHIN, M., 2009a, A fifteen year record of global natural gas flaring derived from satellite data. Energies, 2, pp. 595-622.

ELVIDGE, C.D., BAUGH, K.E., TUTTLE, B.T., ZISKIN, D., GHOSH, T., ZHIZHIN, M., PACK, D.W., 2009b, Improving satellite data estimation of gas flaring volumes. Year two final report to the GGFR. http://www.ngdc.noaa.gov/dmsp/interest/flare_docs/NGDC_flaring_report_20090817.pdf (accessed on 1st February 2011).

EREGHA, P. B., IRUGH, I. R., 2009, Oil induced environmental degradation in the Nigeria's Niger Delta: The multiplier effects. Journal of Sustainable Development in Africa, 11(4), pp. 160-175.

ENVIRONMENTAL RIGHTS ACTION/FRIENDS OF THE EARTH, 2005, Gas flaring in Nigeria: a human rights. Environmental and economic monstrosity. http://www.foe.co.uk/resource/reports/gas_flaring_nigeria.pdf. (accessed on 5th October, 2009)

FLYNN, L.P., HARRIS, A.J.L., WRIGHT, R., 2001, Improved identification of volcanic features using Landsat 7 ETM+. Remote Sensing of Environment, 78, pp. 180-193.

FRANCIS, P.W., ROTHERY, D.A., 1987, Using the Landsat Thematic Mapper to detect and monitor active volcanoes: an example from Lascar volcano, northern Chile. Geology 15, pp. 614-617

FRIENDS OF THE EARTH, 2004a, Shell oil and gas flaring in Nigeria. http://www.foe.co.uk/resource/images/shell_nigeria_2006/slides/EG_Gas\%20flare\%20K olo\%20Creek\%20shot\%201.html (accessed on 5th October, 2009).

FRIENDS OF THE EARTH, 2004b, Gas flaring in Nigeria. Media briefing (accessed on 5th October, 2009). http://www.foe.co.uk/resource/media_briefing/gasflaringinnigeria.pdf (accessed on 5th October, 2009).

FRIENDS OF THE EARTH, 2005, Communities sue Shell to stop Nigerian gas flaring. Archived press release. http://www.foe.co.uk/resource/press_releases/communities_sue_shell_to_s_20062005.ht $\underline{\mathrm{ml}}$ (accessed on 5th October, 2009).

GE ENERGY, 2011, Flare gas reduction: Recent global trends and policy considerations. http://www.geenergy.com/content/multimedia/ files/downloads/GE\%20Flare\%20Gas\%20Reduction\%2 001-24-2011.pdf (accessed on 25th July, 2012)

GIGLIO, L., DESCLOITRES, J., JUSTICE, C.O., KAUFMAN, Y.J., 2003, An enhanced contextual fire detection algorithm for MODIS. Remote Sensing of Environment 8, pp. 273-282.

GAONAC'H, H., VANDEMEULEBROUCK, J., STIX, J., HALBWACHS, M., 1994, Thermal infrared satellite measurements of volcanic activity at Stromboli and Vulcano. Journal of Geophysical Research, 99, pp. 9477-9485.

GIGLIO, L., KENDALL, J.D., 2001. Application of the Dozier retrieval to wildfire characterization: A sensitivity analysis. Remote Sensing of Environment 77, pp. 34-49

ICHOKU, C., KAUFMAN, Y. J., GIGLIO, L., LI, Z. FRASER, R. H., JIN, J.Z., PARK, W. M., 2003, Comparative analysis of daytime fire detection algorithms using AVHRR data for the 1995 fire season in Canada: perspective for MODIS. International Journal of Remote Sensing, 24 (8), 1669-1690. 
IUCN (INTERNATIONAL UNION FOR THE CONSERVATION OF NATURE), 1994, A Guide to the Convention on Biological Diversity. Environmental Policy and Law (30). http://data.iucn.org/dbtw-wpd/edocs/EPLP-no.030.pdf (accessed on 12/10/2011).

JUSTICE, C., GIGLIO, L., BOSCHETTI, L., ROY, D., CSISZAR, I., MORISETTE, J., KAUFMAN, Y., 2006, Algorithm Technical Background Document: MODIS FIRE PRODUCTS. http://modis.gsfc.nasa.gov/data/atbd/atbd_mod14.pdf. (accessed on 10th March, 2011).

KANT, Y, BADARINATH, K.V.S., 2002, Sub-pixel fire detection using Landsat-TM thermal data. Infrared Physics \& Technology 43, pp. 383-387.

KARPOUZLI, E., MALTHUS, T, 2003, The empirical line method for the atmospheric correction of IKONOS imagery. International Journal of Remote Sensing, 24 (5), pp. $1143-1150$.

KAUFMAN, Y.J., JUSTICE, C., FLYNN, L., KENDALl, J., PRINS, E., WARD, D.E., MENZEL, P., SETZER, A., 1998, Monitoring Global Fires from EOS-MODIS. Journal of Geophysical Research, 103, pp. 32215-32338.

KENNEDY, P.J., BELWARD, A.S., GREGOIRE, J.M., 1994, An improved approach to fire monitoring in West Africa using AVHRR data, International Journal of Remote Sensing, 15, pp. 2235-2255.

KIENHOLZ, C., PRAKASH, A., KOLKER, A., 2009, Geothermal exploration in Akutan, Alaska, using multitemporal thermal infrared images. American Geophysical Union, Fall Meeting.

KUENZER, C., ZHANG, J., LI, J., VOIGT, S., MEHL, H. and WAGNER, W., 2007, Detection of unknown coal fires: synergy of coal fire risk area delineation and improved thermal anomaly extraction. International Journal of Remote Sensing, DOI: 10.1080/01431160701250432, 28, pp. 4561-4585

KUENZER, C., HECKER, C., ZHANG, J., WESSLING, S., WAGNER, W., 2008: The potential of multi-diurnal MODIS thermal bands data for coal fire detection. International Journal of Remote Sensing, 29, 923-944.

LAGIOS, E., VASSILOPOULOU, S., SAKKAS, V., DIETRICH, V., DAMIATA, B.N., GANAS, A., 2007, Testing satellite and ground thermal imaging of low-temperature fumarolic fields: The dormant Nisyros volcano (Greece). ISPRS Journal of Photogrammetry and Remote Sensing 62, pp. 447-460.

LANGAAS, S., 1993, A parametrised bispectral model for savanna fire detection using AVHRR night images. International Journal of Remote Sensing, 14, pp. 2245-2262.

LANORTE A., DANESE, M., LASAPONARA, R., MURGANATE, B., 2013, Multiscale mapping of burn area and severity using multisensor satellite data and spatial autocorrelation analysis. International Journal of Applied Earth Observation and Geoinformation, 20, pp. 42-51.

LI, Z., KAUFMAN, Y.J., ICHOKU, C., FRASER, R., TRISHCHENKO, A., GIGLIO, L., JIN, J., AND YU, X, 2000, A review of AVHRR-based active fire detection algorithms: principles, limitations, and recommendations. http://www.fao.org/gtos/gofcgold/docs/fire_ov.pdf. (accessed on 4th February, 2011).

MALINGREAU, J. P., TUCKER, C. J., 1988, Large scale deforestation in the south-eastern Amazon basin of Brazil. Ambio, 17, pp.49-55.

MARTÍN, M. P., FLASSE, S., DOWNEY, I., CECCATO, P., 1999, Fire detection and fire growth monitoring using satellite data. http://publiclibrary.rfs.nsw.gov.au/CommonDocuments/7300FiredetectionMicrosoft $\% 20$ Word\%20-\%20review.pdf. (accessed on 10th March, 2011).

MATSON, M., DOZIER, J., 1981, Identification of subresolution high temperature sources using a thermal IR sensor. Photogrammetric Engineering and Remote Sensing, 47, pp. 1311- 1318. 
MOVAGHATI S., SAMADZADEGAN F., AZIZI A., 2009, An Agent-Based Approach for Regional Forest Fire Detection using MODIS Data. Journal of Applied Sciences 9 (20), pp. 3672 - 3681.

MUIRHEAD, K., CRACKNELL, A.P., 1984, Identification of gas flares in the North Sea using satellite data. International Journal of Remote Sensing, 5, (1), pp. 199 - 212.

NASA (NATIONAL AERONAUTICS AND SPACE ADMINISTRATION) (), 2011, Level 1G product. Landsat 7 science data users handbook. http://landsathandbook.gsfc.nasa.gov/data_prod/prog_sect11_3.html (accessed on 12th May 2011)

NIGER DELTA AWARENESS, 2007, Geo-Ethnographic Description. http://www.nigerdeltaawareness.com/GeoEthnicDescription.htm.

NIGERIAN CONSERVATION FOUNDATION, 2006, Niger Delta named most polluted ecosystem in the world. News/Publications. Lekki Conservation Centre, Lagos, Nigeria. $\quad$ http://www.ncfnigeria.org/web/inthenews/news_feeds.php?article=21 (accessed on $11^{\text {th }}$ July, 2010).

NLNG (NIGERIA LIQUEFIED NATURAL GAS), 2008, Gas flaring. Environmental management publication. http://www.nigerialng.com/NLNGnew/environment/NLNG+and+Gas+Reserves.htm (accessed on $11^{\text {th }}$ July, 2010).

NLNG (NIGERIA LIQUEFIED NATURAL GAS), 2012, NLNG and gas reserves. Our Environmental publication. http://www.nlng.com/PageEngine.aspx?\&id=87 (accessed on 08 $8^{\text {th }}$ December, 2012).Nigeria National Petroleum Corporation - NNPC, 2011. Annual statistics bulletin. http://www.nnpcgroup.com/PublicRelations/OilandGasStatistics/AnnualStatisticsBull etin/MonthlyPerformance.aspx . (accessed on $8^{\text {th }}$ December, 2012).

NNPC (Nigeria National Petroleum Corporation) 2011, Annual statistics bulletin. www.nnpcgroup.com . accessed on 10 $0^{\text {th }}$ March, 2012).

NZEWUNWA, N, 1979, Aspects of economy and culture in the prehistory of the Niger Delta. PhD. thesis, St. Johns College, Cambridge.

NWAOGU, L.A., ONYEZE, G.O.C., 2010, Environmental Impact of Gas Flaring on EbochaEgbema in the Niger Delta. Nigerian Journal of Biochemistry and Molecular Biology. 25 (1), pp. 25-30.

ODU, C.T.T., 1994, Gas flare emissions and their effects on the acidity of rain water in the Ebocha area. Department of Agronomy, University of Ibadan. Ibadan.

OLUKOYA, S., 2008, Nigeria: Inefficient gas flaring remains unchecked. Johannesburg: Inter Press Service. http://www.ipsnews.net/2008/01/climate-nigeria-inefficient-gas-flaringremains-unchecked/. (accessed on $5^{\text {th }}$ April, 2011).

PETERSON, D., WANG, J., ICHOKU, C., HYER , E., AMBROSIA, V., 2013, A sub-pixelbased calculation of fire radiative power from MODIS observations: Algorithm development and initial assessment. Remote Sensing of Environment 129, pp. 262279

PRAKASH, A., GUPTA, R.P., SARAF, A.K., 1997, A Landsat TM based comparative study of surface and subsurface fire in the Jharia Coal Field, India. International Journal of Remote Sensing 18 (11), pp. 2463-2469.

PRINS, E.M., MENZEL, W.P., 1992, Geostationary satellite detection of biomass burning in South America. International Journal of Remote Sensing, 13 (15), pp. 2783-2799.

ROBERTS, G.J., WOOSTER, M.J., 2008, Fire detection and fire characterization over Africa using Meteosat SEVIRI. IEEE Transactions on Geoscience And Remote Sensing, 46 (4), pp. $1200-1218$.

ROBINSON, J.M., 1991, Fire from space: Global fire evaluation using infrared remote sensing, International. Journal of Remote Sensing, 12, pp. 3-24. 
SAVAGE, S, 2009, Evaluating the use of landsat imagery for monitoring geothermal heat flow in Yellowstone National Park. Final report to Yellowstone National Park, the Department of Interior of the United States Government.

SCHMIDT, C.C., PRINS, E.M., 2005, The goes wildfire automated biomass burning algorithm and its applications. East Fire Conference, Virginia, United States.

SEDANO, F., KEMPENEERS, P., SAN MIGUEL, J., STROBL, P., VOGT, P., 2013, Towards a pan-European burnt scar mapping methodology based on single date medium resolution optical remote sensing data. International Journal of Applied Earth Observation and Geoinformation, 20, pp. 52-59.

SETZER, A. W., PEREIRA, M. C., 1991, Amazonia Biomass Burnings in 1987 and an Estimate of their tropospheric emissions. Ambio, 20, pp. 19-22.

SPDC (SHELL PETROLEUM DEVELOPMENT COMPANY OF NIGERIA), 2011, Shell in Nigeria: Gas flaring. $\quad$ http://wwwstatic.shell.com/static/nga/downloads/pdfs/briefing_notes/gas_flaring.pdf. (accessed on $8^{\text {th }}$ December, 2011).

TUTTLE, M.L.W., CHARPENTIER, R.R., BROWNFIELD, M.E., 1999, The Niger Delta Petroleum System: Niger Delta Province, Nigeria, Cameroon, and Equatorial Guinea, Africa. U. S. Department of the Interior. U.S. Geological Survey report.

UGOCHUKWU, C.N., 2008, Sustainable Environmental Management in the Niger Delta Region of Nigeria: Effects of Hydrocarbon Pollution on Local Economy. PhD Thesis, Brandenburg University of Technology (BTU), Cottbus, Germany.http://opus.kobv.de/btu/volltexte/2008/569/pdf/Collins Ugochukwu PhD D issertation.pdf (accessed on $8^{\text {th }}$ November, 2010).

USGS (U.S. GEOLOGICAL SURVEY), 2012, Global Visualization Viewer. http://glovis.usgs.gov.

VANGUARD NEWSPAPER, 2012,_Nigeria's daily crude production to hit 4million barrels by 2020. http://www.vanguardngr.com/2012/11/nigerias-daily-crudeproduction-to-hit-4million-barrels-by-2020/ (accessed on $8^{\text {th }}$ December, 2012)

VANGUARD NEWSPAPER, 2011, Nigeria's crude oil production rises to $2.6 \mathrm{~m}$ $\begin{array}{llll}\text { barrels } & \text { daily } & - & \text { FG. }\end{array}$ http://www.vanguardngr.com/2011/02/nigeria\%E2\%80\%99s-crude-oilproduction-rises-to-2-6m-barrels-daily-fg/ (accessed on $8^{\text {th }}$ December, 2012)

WEAVER, J. F., LINDSEY, D. T., BIKOS, D. E., SCHMIDT, C. C., PRINS, E., 2004, Fire detection using GOES-11 rapid scan imagery. Weather and Forecasting, 19, 496-510.

WOOSTER, M.J., XU, W., NIGHTINGALE, T., 2012, Sentinel-3 SLSTR active fire detection and FRP product: Pre-launch algorithm development and performance evaluation using MODIS and ASTER datasets. Remote Sensing of Environment, 120, pp. 236254.

WORLD BANK., 2012, World Bank urges oil producers to reduce gas flaring, increase gas utilisation for development. Press release. http://www.worldbank.org/en/news/2012/10/24/world-bank-urges-oil-producersreduce-gas-flaring-increase-gas-utilization-development. (accessed on $8^{\text {th }}$ November, 2012).

WORLD BANK, 2004, Gas flaring and venting a regulatory framework and incentives for gas utilization. http://rru.worldbank.org/documents/publicpolicyjournal/279gerner.pdf (accessed on 8/11 2010).

WORLD BANK, 2002, Global gas flaring reduction initiative: Report on consultation with stakeholders.

ZABBEY, N., 2004, Impacts_of extractive industries on the biodiversity of the Niger Delta region, Nigeria. Paper presented at a 3-Day National Workshop on Coastal and Marine Biodiversity Management. Head, Conservation Programme, Center for 
Environment, Human Rights and Development (CEHRD), Eleme, Rivers State, Nigeria.

ZHUKOV, B., LORENZ, E., OERTEL, D., WOOSTER, M.J, ROBERTS, G., 2006, Spaceborne detection and characterization of fires during the bi-spectral infrared detection (BIRD) experimental small satellite mission (2001-2004). Remote Sensing of Environment, 100, pp. 29-51. 